\title{
Assessment Driven Change: How Systemic Evaluation Can Lead to More Productive Outreach
}

\author{
Barbara Bogue \\ The Pennsylvania State University
}

Assessment is often the weakest part of apparently successful outreach activities. While most outreach activities include surveys of participants as a part of the activity, the surveys are typically formative and one-time. $(3,6)$. Furthermore, because these are typically given at the end of the event when participants are revved up, the responses measured are a better indication of a participant's enjoyment rather than whether the objectives of the activity were met. Without verification through other data (a post-event survey or tracking of subsequent decisions and actions), the information gathered is effective primarily for guaranteeing the development of an activity that the participants enjoy.

While it is certainly important for the success of a program to have the participants enjoy it, from the point of view of larger goals and objectives, it is inadequate. If for example, the goal of the activity was to have pre-college girls take more math or enroll in engineering at the University level or to have a lasting understanding of what engineers do, this is not measured by a sole formative survey offered at the end of the activity. In fact, this lack of data on whether objectives of pre-college engineering outreach activities may well be one of the factors in the plateau of women in engineering undergraduate programs at an average 20 percent nationally. The NSF report on Building Science and Engineering Talent (2) identifies the lack of good assessment and the resulting data as one of the major issues to be addressed in the recruitment and retention of underrepresented minorities in engineering.

Ultimately, good assessment requires a systems approach to gathering and analyzing data. By combining formative and summative information with other sources of data such as a timemanagement student, resource allocation analysis and traditional outcomes tracking of what happens to participants after they complete an activity provides an overall picture valuable for enhancing, redirecting or even dropping an outreach effort. This paper presents such an overall analysis of an engineering outreach camp for girls offered annually at Penn State's University Park campus.

\section{Description and history of the camp}

MTM High School Day Camp (Move the Mountain) started out as VEC-Tour (Venture in Engineering Camp) a traditional residential camp designed to introduce junior and senior high school girls to engineering in 2001. A secondary, and specific goal, was to recruit the girls to Penn State Engineering. Today, it is an engineering day camp offered annually in the center of Pennsylvania that attracts a diverse group of girls from states that have included Georgia, Texas and Wisconsin. The participants are diverse: Thirty-five percent of the girls participating in 2003 were African American (14\%) and Hispanic American (21\%). Only 30 percent of the campers 
were from the immediate area. And it is growing: Ninety students attended MTM 04, up from 60 in MTM 03. The camp diversity was achieved through a targeted effort and development of pipelines to the camp. (7)

The story of why we converted from a traditional residential camp and how we attract girls from all over the country to an engineering day camp in Central PA is a story of the use of a variety of assessment tools to effectively evaluate and revamp a new outreach initiative.

Objectives of the camp were:

1) Introduce girls not identifying engineering as a potential major, to engineering.

$\Rightarrow$ Expected Outcome: High percentage of uncommitted girls who become interested

2) Recruit girls to Penn State.

$\Rightarrow$ Expected Outcome: Girls apply to Penn State

3) Provide leadership experience for upper-level women.

$\Rightarrow$ Expected Outcome: Women retained at higher level; increase commitment to engineering

The initial target audience for participants was rising junior and senior high school girls not identifying engineering as a possible path. The target group was chosen deliberately: Too often girls with the promise and interest unknowingly narrow their options because they have not received the necessary support (1), encouragement or basic information. MTM is designed to reach them at a pivotal time to reinforce their interest and participation in math and science and to encourage them to continue to take the coursework necessary to succeed in an engineering discipline. The camp also provides undergraduate and graduate women with leadership opportunities as they role model positive behavior for campers.

In brief, the camp is typical of many such offerings, designed as a comprehensive, integrated pipeline program designed to recruit, retain and develop future women engineers through integrated activities, introducing girls to fields and opportunities that will encourage them to enter, continue and excel in engineering. Primary delivery of information is through hands on activities that:

- Emphasize interdisciplinary activities

- Introduce key technologies and practices related to engineering

- Develop problem solving, teamwork and business skills

- Emphasize real world engineering experience through hands-on projects and case study focused activities

- Provide contact with engineering professionals through networking and related activities

To assess the initial offering, we administered pre- and immediate post-camp surveys and results indicated that the initial camp offering was a success: in the pre-camp survey, $5 \%$ of participants indicated that they wanted to become engineers as compared with $100 \%$ in the post-camp survey. The post-camp survey also showed that 13 of 15 senior participants $(87 \%)$ indicated their intent to study engineering at Penn State. In post-camp survey items that gathered formative and 
student satisfaction data, participants also reported high approval ratings of the camp organization, hands-on activities and mentors. All of the leadership indicated that the camp was a positive experience.

\section{Combining Assessment Results to Create an Innovative Day Module Concept}

The formative instrument was a good tool for developing customer satisfaction (e.g. whether participants enjoyed the activities, liked engineering now that they had sampled it, understood basic engineering disciplines, meeting with engineering women, meeting each other, and the camp overall) but it did not provide information on whether the camp objectives were met in the long term. As noted above, the girls responded enthusiastically to the survey administered at the end of the original camp, but this is arguably more a measure of how much they enjoyed the experience rather than a reliable predictor of a long-term commitment to engineering.

The original plan was to administer a post-survey six months after the event. Unfortunately, staffing and funding changes prevented this so we had to look for other data to help evaluate how effective the camp was. (It should be noted that the camp now administers a post-survey and is a participant in the AWE (Assessing Women in Engineering-NSF (HRD 01 20642) Assessment project (8)). We did this in three ways, by checking to see which of the camp participants actually enrolled in Penn State engineering; by calculating how much per camper we were expending and looking at that amount in terms of the overall Women in Engineering Program budget; and by undertaking an analysis of how participants spent their time. The underlying question: Is the camp worth the time, people and financial resources expended?

As noted above, 13 of the 15 seniors attending the original camp indicated an intention of attending Penn State in engineering. In fact, a check of the application and enrollment data indicated that only two actually applied to Penn State and only one of those was accepted at University Park (both did enroll and are currently retained in the curriculum). At this point in the analysis we did not have the enrollment figures for the juniors who participated. That figure was better with four women going on to matriculate at Penn State in engineering.

A look at the overall budget showed an even more discouraging story. The pilot offering came out to a cost of almost $\$ 1500 /$ girl. While that number would have gone down in subsequent offerings and was defrayed by camp registrations, it was high. Offering individual scholarships to a selection of top girls would have been a simpler and probably a more effective recruiting tool.

The time analysis was the most revealing (see Figure 1, next page): Only $10 \%$ of camp time was actually spent on engineering with the greatest bulk of time dedicated to maintenance activities like sleeping (39\%) and eating (15\%), followed closely by logistics (12\%). Significantly, these are items represent 73 percent of participant time on campus that did not use the expertise or training of the staff effectively. Overall, we were directly addressing our objectives only 27 percent of the time (tours, teamwork, engineering and computer/math.) Clearly, this was a 24/7 effort that not only did not effectively address our objectives, but also distracted valuable staffing time from mission-based activities. 


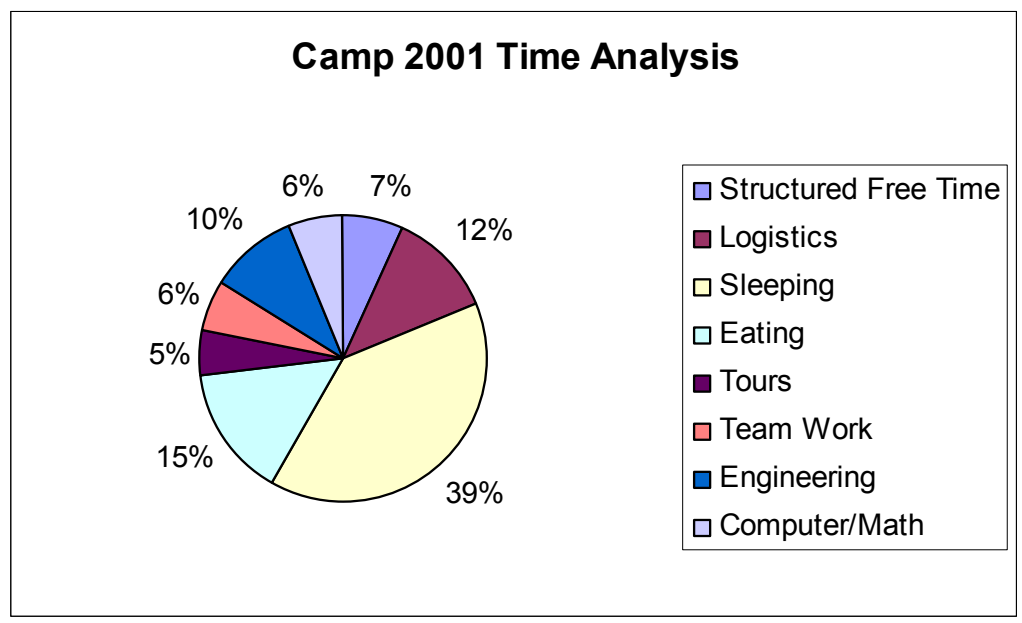

Figure 1: Time Analysis of Original Camp

Combining the assessment data provided a very different picture than that provided by the participants in the flush of the camp finale: the camp was successful in introducing girls to engineering as a fun, participatory activity but the "halo" or longer term effect did not yield real enrollment results and the time and cost analysis indicated something that actually looked like failure.

All data, however, provided a more accurate picture of the camp outcomes relative to objectives and helped to pin-point where change was needed. Other organizational revisions included:

- Eliminating as many non-engineering activities as possible.

- Combining engineering activities into logistics whenever possible

- Focusing camp time on delivering hands-on engineering experiences that directly address camp objectives.

Once we had the combined data in hand, the questions became obvious: how to better meet objectives, increase cost effectiveness, and use our limited staff to best advantage. The idea of converting to a day camp surfaced fairly early, with the biggest disadvantage being our location in a small town equally distant from everywhere. The advantages, however, outweighed this concern.

A day camp would allow us to:

- Avoid many of the complications and expenses of a residential camp, and use the talents of staff and administrators in areas where they have training and experience.

- Increase the recruitment yield. From the original '01 offering, 2 women matriculated at Penn State in '02 and 4 in '03. By MTM '03, five seniors went on to Penn State in Engineering.

- Better attract our targeted audience. In the first offering, we were able to identify and attract this group but they were not, in the beginning, happy campers. Considerable effort was required during the first two days to convince them that their parents' decision that they should attend was a good one. With the day module, girls reported no reluctance to experiment and "try out" engineering.

- Offer the camp much more cheaply. MTM '03 came in at a cost of $\$ 428$ /girl overall (compared to the initial \$1500/girl) and \$142/girl by daily participant. (Sixty-eight girls 
participated overall but some of those attended multiple modules. The participation count was 190.) MTM ’04 came in at \$191/girl overall and \$121/girl by daily participation.

- Serve and recruit more girls. The day module camp has the potential of serving 350 girls, as compared to 50 girls in the residential model. (The 350 total reflects our ability to add concurrent sessions to a day with increased demand and as our staffing and coordination allow. In theory, the size of the camp is limited only by our ability to provide the staffing to keep each module experience small and effective. )

- Be more flexible. The camp is now designed so that we can begin to offer one-day activities based on the modules. We can also add modules for days that have a high number of registrants.

- Direct our human and financial resources towards achieving the stated objectives. As seen in figure 2, the pieces of the pie dedicated to the objectives rose dramatically with 76 percent of the time now going to engineering related activities.

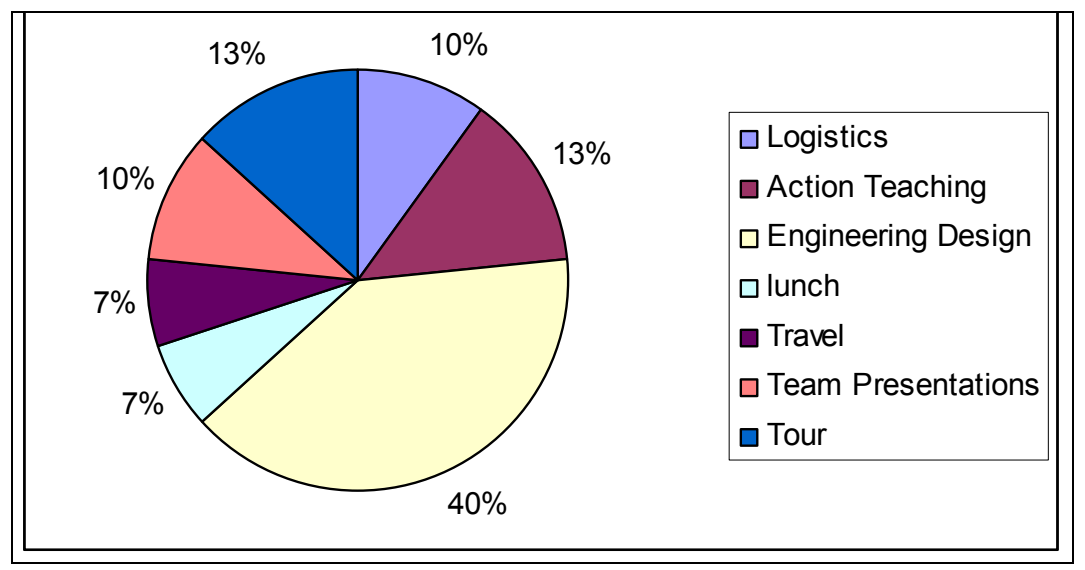

Figure 2: Time Analysis of Revamped Camp

The result was migration of the camp objectives and goals to a day camp model that used the elements of the initial camp but eliminated as many of the extraneous (and distracting) activities as possible.

The interdisciplinary hands on engineering modules developed for the original camp were offered as daily activities - girls could choose to go to as few or as many as they registered for. Each module features an active learning experience, exposure to strong role models and engineering career information related to the module. The modules are all interdisciplinary, introducing girls to engineering through interdisciplinary laboratory experiences. This approach addresses many of the issues that girls face in understanding engineering contextually. (1) Accordingly, MTM aims to prepare girls to succeed through cross-cultural communications experiences, hands on engineering skills workshops, career preparation, and active networking. MTM uses targeted cross disciplinary activities to introduce engineering to girls as a broad, dynamic and people oriented profession at a time when they are making critical educational decisions. 
Each day module features an interdisciplinary look at engineering through topics such as sustainable development, bioengineering, robotics or entrepreneurship. Activities during the day include an overview of the subject area, an introduction to the types of engineering majors involved, a hands-on design project and a tour to a relevant company or University project. (7)

All modules are led and developed by faculty, graduate women or Women in Engineering Program staff. For example, WEP associate director and ceramic engineer Cheryl Knobloch, a ceramic engineer, engaged girls in ethics and socially conscious engineering, asking them to design physical environments for the physically handicapped. In another example, two architectural engineering graduate women, Amy Grommes and Priya Premchandran, designed a day module on Environmental Construction and Design based on their experience in developing hay bale housing designs for Native Americans. Another module, designed by Nadine Barrie Smith, assistant professor in bioengineering, has participants construct and test a EKG machine.

An important feature of MTM is the leadership opportunities offered to upper level engineering and graduate women students. This is a successful, combined retention and recruitment strategy. The undergraduate mentor/instructors provide strong and active role models and leadership for younger students at the same time that they solidify their own skills, confidence, and identification with and commitment to engineering. The younger mentor/facilitators themselves will learn and master skills as they to teach them to others. At a time when these young women may be questioning their own abilities, they develop confidence by teaching those younger, acting as positive role models, and increasing their sense of connection with the College, other engineering students, and the engineering profession.

\section{Conclusion}

Lessons learned include:

- Poor data or incomplete data can lead to wrong overall evaluation and negatively impact subsequent planning and decision making

- Good data from multiple sources can lead to more accurate assessment and enhancement of activities

- Effective assessment may be painful but can lead to better programming that achieves projected outcomes.

Based on assessment, Penn State's Women in Engineering Program converted a traditional residential week-long camp for high school girls to a modular day camp. The camp now better serves the stated objectives, has the potential to serve far more girls, and is much cheaper to run, both in terms of human and financial resources. Pre- and Post-assessment instruments are now in use, which will help to determine how effective the new model is. Other measures, such as numbers of girls attracted, the distance they are willing to travel to participate, and the cost and time effectiveness are all positive.

\section{Acknowledgements}

MTM is supported by donations from the Penn State Equal Opportunity Planning Committee, 3M Corporation, Alcoa, Daimler-Chrysler, Dow Chemical, Lockheed Martin, Merck Corporation Foundation, Siemens Corporation and Unysis. Cheryl Knobloch, associate director 
of the Penn State Women in Engineering Program oversaw coordinates the camp and has continued to develop MTM as an effective recruiting tool.

\section{Bibliography}

1. AAUW Educational Foundation Commission on Technology, Gender, and Teacher Education. (2000). Tech-Savvy: Educating Girls in the New Computer Age. AAUW Educational Foundation.

2. Barton, C., Chubin D; Rodriguez. C., Rosen, L, Ward, W, Yochelson, J. (2002) The Talent Imperative in Science and Engineering: A Two-Year Net Assessment. Power Point Report of Activities of BEST (Building Science and Engineering Talent). NSF, Directorate for Education and Human Resources, Division of Human Resource Development: "Making a Difference"

3. Bogue, B., \& Marra, R. (2001). Informal Survey of WIE Directors. University Park, PA: Penn State University.

4. Bogue, B., R.M. Marra, Effective Assessment as a Tool to Develop and Enhance WIE / WISE Programs, WEPAN National Conference, Chicago, IL. 2003.

5. Engineering Workforce Commission of the American Association of Engineering Societies, Inc

6. Goodman, I.F.; Cunningham, C.M.; Lachapelle, C.; Thompson, M.; Bittinger, K.; Brennan, R.T.; \& Delci,. M. (2002). Final report of Women's Experiences in College Engineering (WECE) Project. Cambridge, MA: Goodman Research Group Inc. Retrieved November 10, 2003, from http://www.gginc.com.

7. Knobloch, Cheryl. (2005). The Pennsylvania State University "MTM Engineering Camp for Girls": Generating Under-represented Pathway Prospects Through a Diversity-Rich Pre-College Outreach Project. WEPAN/NAMEPA 2005 Proceedings. (In Press).

8. Marra, R., Bogue, B. (2004). "The Assessing Women in Engineering (AWE) Project: A Model for Sustainable and Profitable Collaboration". Journal of Women and Minorities in Science and Engineering,_10(3), 283 - 295.

BARBARA BOGUE is Associate Professor of Engineering Science and Mechanics and Women in Engineering. She is co-PI of AWE and former director of the Penn State Women in Engineering Program. Her research interests include recruitment and retention of women in engineering, assessment and career development. 